\title{
FORECASTING CROWDFUNDING PLATFORM REVENUES USING ARIMA MODEL
}

\author{
Santautė VENSLAVIENE் (D), Jelena STANKEVIČIENE் (D) \\ Department of Financial Engineering, Faculty of Business Management, \\ Vilnius Gediminas Technical University, Sauletekio al. 11, LT-10223 Vilnius, Lithuania
}

Received 28 February 2021; accepted 01 April 2021

\begin{abstract}
Purpose - In recent years, crowdfunding platforms have become very popular as intermediaries between fundraisers and funders. However, various campaigns published on the platform might be of bad quality or fraudulent, so the crowdfunding platform must be very careful when choosing the right ones. Also, the proper selection depends on the profits of a crowdfunding platform. In most cases, crowdfunding platforms mainly earn money from transaction and administration fees from successful campaigns on their platforms. While it is very hard to select successful campaigns, it is possible to analyse already published campaigns and forecast future revenues of crowdfunding platforms. And based on this, to select new projects which might be successful too. The aim of this work is to develop a model to forecast the revenues of crowdfunding platforms.

Research methodology - In this research, comparative and statistical analysis will be used, data structuring, modelling and forecasting, performed with the ARIMA model.

Findings - Main findings of this research present the three most successful campaign categories from the Kickstarter platform that receives the highest funding. Fees were calculated from those three campaign categories, and revenues for the platform were forecasted using the ARIMA model.

Research limitations - Main limitations are that there were used data from a very short period of time. For better results accuracy, a longer period is needed.

Practical implications - this research might be of practical use since the forecasts show that the revenues will continue to grow from the successful campaign categories. Consequently, investors should continue to support technology, games and design categories the most. At the same time, crowdfunding platforms should give more attention to these categories when choosing new projects to launch on the platform.
\end{abstract}

Keywords: crowdfunding, a crowdfunding platform, funding, revenues, forecast, ARIMA model, successful campaigns.

JEL Classification: G17, G23.

Conference topic: Contemporary Financial Management.

\section{Introduction}

Crowdfunding is a recent and still evolving phenomenon that has attracted public interest. Crowdfunding is an emerging alternative form of financing that connects those who can invest money directly with those who need funding for a specific project (Gierczak et al., 2014; Thies et al., 2014). Especially, crowdfunding platforms have become popular for publishing project ideas and collecting funding (Salomon, 2016). But how do crowdfunding platforms work and how do they receive main profits? In most cases, crowdfunding platforms earn money from transaction and administration fees from successful campaigns on their platforms. Since campaigns are of different quality, a fee per campaign may serve as a screening device to limit "bad" campaigns on the platform (Belleflamme et al., 2015). This may reduce the required search effort by funders and thus make the platform more attractive. Since, there are various ways to select crowdfunding platform for investment and for funding, high revenues might display crowdfunding platform's reliability and stability. Also, the right selection depends on the profits of a crowdfunding platform. While it is very hard to select successful campaigns, it is possible to analyse already published campaigns and forecast future revenues of crowdfunding platforms. And based on this, to select new projects which might be successful too. In this research, crowdfunding platforms' revenues will be calculated and then forecasted using the ARIMA model in Python statistical software.

*E-mail: santaute.venslaviene@vilniustech.lt

(C) 2021 Authors. Published by Vilnius Gediminas Technical University. This is an open-access article distributed under the terms of the Creative Commons Attribution (http://creativecommons.org/licenses/by/4.0/) License, which permits unrestricted use, distribution, and reproduction in any medium, provided the original author and source are credited. 


\section{Literature review}

\subsection{Crowdfunding platform success from funded campaigns}

Crowdfunding has become a novel and popular financing channel worldwide (Vroomen \& Desa, 2018). The first studies that focused on equity crowdfunding platforms discussed the general functioning of this new financing form and compared the decision-making process of equity crowdfunding with that of traditional venture capital funding (Hagedorn \& Pinkwart, 2016; Löher, 2017; Salomon, 2016). However, the success rate of crowdfunding campaigns on most platforms is less than 50\% (Lukkarinen et al., 2016; Zhao et al., 2017). Therefore, project supporters should not only try to attract more visitors but also understand their funding intention, which is predominantly important in increasing the success of crowdfunding as an alternative instrument of financing (Gierczak et al., 2014). With the intention of a better understanding of crowdfunding dynamics and improving campaign success rates on the financing stage of crowdfunding, knowledge of the factors contributing to success in crowdfunding is required (Fan-Osuala et al., 2018). With the increasing number of crowdfunded projects, it is important to understand what drives people to either create or fund these projects (Gerber \& Hui, 2013). Using social capital theory (Butticè et al., 2017; Colombo et al., 2015; Skirnevskiy et al., 2017), signal theory (Ahlers et al., 2015; Courtney et al., 2017), the herding effect (Mohammadi \& Shafi, 2018), and local bias (Mendes-Da-Silva et al., 2016), many factors that affect the success of crowdfunding campaigns were found.

On the contrary, it is very important to know what factors affect equity crowdfunding platforms to launch projects online in the pre-investment stage (Zhang et al., 2018). The behaviour of crowdfunding platforms for selecting crowdfunding projects should be investigated. Entrepreneurs must submit well-prepared project applications to the platform. Applications should include detailed information about projects, the team, and financials. According to Cumming and Zhang (2017), after successful applications, the crowdfunding platform will ask companies to perform due diligence efforts, including background checks, credit checks, account monitoring, legal cross-checks, site visits, and third-party proof. These efforts not only positively impact funding success but also help to increase the total amount of capital raised (Ralcheva \& Roosenboom, 2019). Project owners spend weeks building their project pages, shooting their videos, and brainstorming what rewards to offer backers (Kickstarter, n.d.-a). It has happened that both Kickstarter and project creators have cancelled projects that appeared to have been fraudulent. Questions were raised about the projects in internet communities related to the fields of the projects. The concerns elevated were: apparent copying of graphics from other sources, unrealistic performance or price claims, and failure of project sponsors to deliver on prior Kickstarter projects.

Since it is still hard to decide for platforms which projects should be launched online or which not, we will try to observe already existing projects which are based on the Kickstarter platform. Kickstarter is an American public-benefit corporation based in Brooklyn, New York that maintains a global crowdfunding platform focused on creativity. This platform is one of the largest and longest working in the world. Kickstarter applies a 5\% fee on the total amount of the funds raised. Their payments processor applies an additional 3-5\% fee. Unlike many forums for fundraising or investment, Kickstarter claims no ownership over the projects and the work they produce. Consequently, Kickstarter gets their profits mainly from applied fees from successfully funded projects. If the project is unsuccessful, the platform does not get anything. It is an all-or-nothing approach applied in the Kickstarter platform.

\subsection{Price structure of Crowdfunding platforms}

Overall, Crowdfunding platforms have up to three revenue sources. First, crowdfunding platforms earn interest on the money, which is dedicated to a given campaign. Second, some Crowdfunding platforms offer additional services for which they charge. For example, many charges for handling payments or they can also offer third-party services and obtain revenues from third-party providers like project support or subscription fees. Third, many crowdfunding platforms charge a transaction fee. This fee usually is taken if the campaign is successful. Alternatively, the Crowdfunding platform could also charge fees to become a member or for a subscription for a certain period (Belleflamme et al., 2015).

On most crowdfunding platforms, fundraisers are not able to choose between different price options. Nevertheless, sometimes there can be an exception like in Indiegogo crowdfunding platform. For example, in the All-or-nothing model, the fundraiser gets the total money guaranteed by the funders only if the specified goal has been reached at the end of the campaign period, while the Keep-it-all model differs by allowing the fundraiser to keep the money raised even if it fails to meet the goal.

Mostly fees are taken, particularly from fundraisers. Since campaigns are of different quality, a fee per campaign may serve as a screening device to limit "bad" campaigns on the platform (Belleflamme et al., 2015). This may reduce the required search effort by funders and thus make the platform more attractive. 


\subsection{Time series forecasting using the ARIMA model}

Time series forecasting is an important area of forecasts in which previous observations of the same variable are collected and analysed in order to develop a model describing the underlying relationship (Zhang, 2003). Popularly known as the Box-Jenkins (BJ) methodology, but technically known as the ARIMA methodology, the emphasis of these methods is not on constructing single-equation or simultaneous-equation models but on analysing the probabilistic, or stochastic, properties of economic time series on their own under the philosophy let the data speak for themselves (Gujarati, 2004; Shim, 2000). The ARIMA model is one of the most well-known methods of financial forecasting, and it has shown an effective opportunity to generate short-term forecasts. In an autoregressive integrated moving average model (ARIMA), the future value of a variable is assumed to be a linear function of several past observations and random errors (GeeksforGeeks, n.d.; Zhang, 2003). The model can be expressed by the formula:

$$
Y_{t}=\varphi_{0}+\varphi_{1} Y_{t}-1+\varphi_{2} Y_{t}-2+\ldots+\varphi_{p} Y_{t}-p+\varepsilon_{t}-\theta_{1} \varepsilon_{t}-1-\theta_{2} \varepsilon_{t}-2-\ldots-\theta_{q} \varepsilon_{t}-q,
$$

where: $Y_{t}$ - actual value at time period $t, \varepsilon_{t}$ - random error at time period $t, \varphi_{i}$ and $\theta_{j}$ - coefficients, $p$ and $q-$ are integers and often referred to as orders of the model. They usually represent autoregressive and moving average.

Looking at time series, it is hard to know whether it follows a purely AR process, or a purely MA process, or an ARMA process, or an ARIMA process. The Box-Jenkins methodology can help to find out what kind of process it is. The method consists of four steps which are shown in Figure 1.

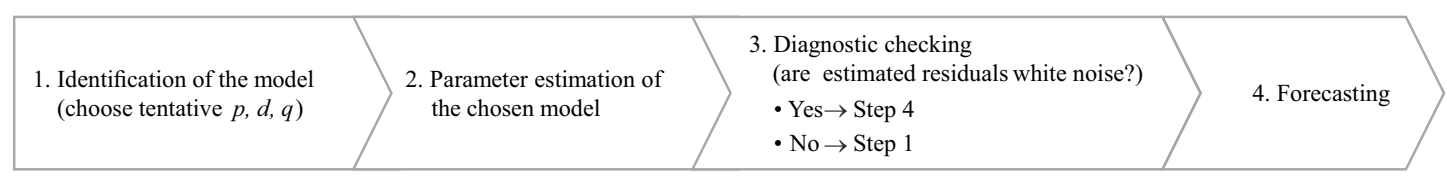

Figure 1. Box-Jenkins methodology for selecting the ARIMA model (source: Gujarati, 2004)

With the purpose to choose the right process, Box-Jenkins methodology can help, which consists of four main steps. First, the identification of the model. Here correlograms and partial correlograms can help. Second, parameter estimation of the chosen model. In this step, parameters of autoregressive and moving average should be evaluated. Third, diagnostic checking should be performed. It should be checked whether the chosen model fits data well. In other words, estimated residuals should be white noise. And if it is not white noise, the Box-Jenkins methodology should be followed again from the first step. And the last step is forecasting. With the chosen model, forecasts can be made.

\section{Methodology}

\subsection{Data}

With the purpose of analysing which project categories are most successful and profitable for crowdfunding platforms, daily data was collected. The data was taken from Kickstarter, one of the biggest crowdfunding platform in the world, the website for the period from November 21, 2020, to February 20, 2021 (Kickstarter, n.d.-b). For the analysis, daily data was collected from four groups: All statistics, Projects and dollars, Successfully and unsuccessfully funded projects.

\subsection{Methods applied}

Having the collected data, the comparative and statistical analysis was made for the whole overview of crowdfunding platform projects. Later, the most profitable and successful projects categories were identified and analysed together and separately.

These project categories were compared to each other, and data was structured. Finally, crowdfunding platform revenues were calculated from successfully invested projects in most profitable project categories.

Finally, crowdfunding platform revenues should be forecasted. For this, the ARIMA model should be identified and created. Forecasts for the future revenues of the crowdfunding platform should be estimated using the created ARIMA model. The overall methodology is shown in Figure 2.

Figure 2 describes the methodology applied in this research. First of all, several crowdfunding platform campaigns were analysed and identified the most successful campaign categories. Campaign categories were compared, and the data was structured. Later, crowdfunding platform revenues were calculated from the most successful crowdfunding project categories. Finally, the crowdfunding platform calculated revenues were forecasted. For this, the ARIMA model was identified and created using the Box-Jenkins methodology.

In the following section, it will be analysed invested projects into the crowdfunding platform Kickstarter. 


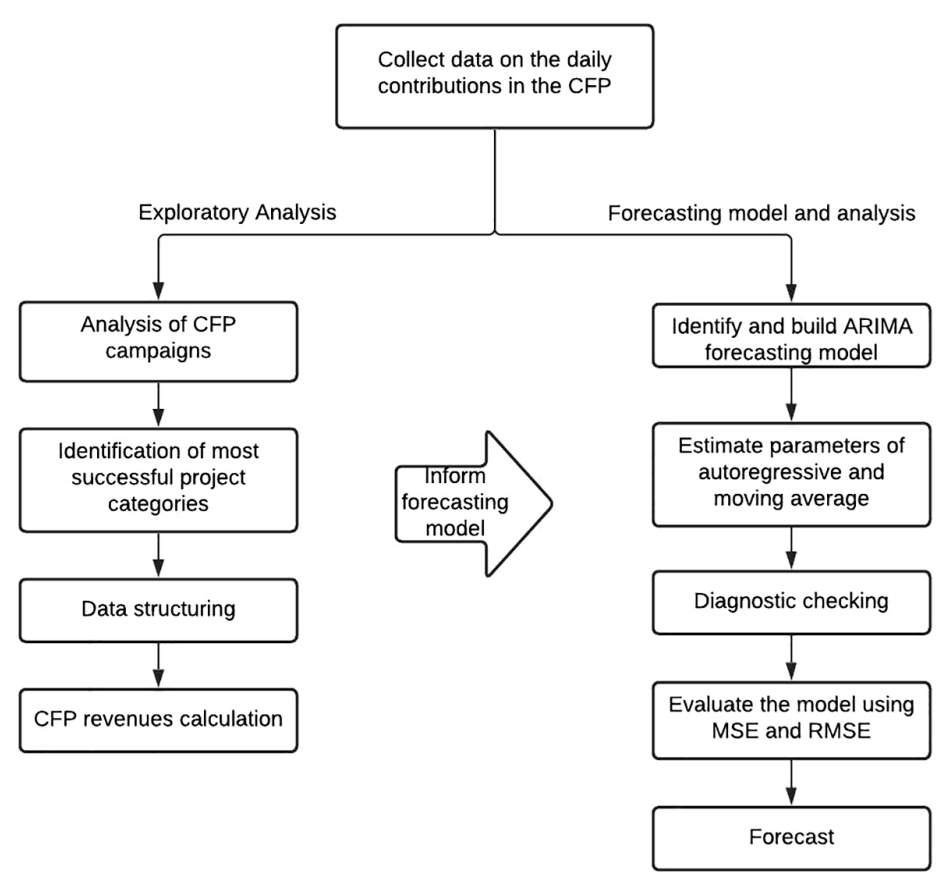

Figure 2. The methodology of research used for crowdfunding platform revenues forecasting (source: created by authors)

\section{Forecasting crowdfunding platform revenues}

\subsection{Analysis of crowdfunding campaigns}

Kickstarter crowdfunding platform was established in 2009, and since then, they have launched 514831 projects, from which only 196562 (38\%) were successfully funded. Unsuccessfully funded projects are $315009(61 \%)$ and live projects $3260(1 \%)$. Based on this, more than $60 \%$ of projects did not receive investors interest.

The platform itself is considered successful since it has a high number of backers. As per February 20, 2021 data, there are more than 19 million total backers, and approximately 6.5 million are repeat backers.

Kickstarter crowdfunding platform specialises mainly in creative projects and suggests 15 different project categories to invest in. Overall, it was invested 5.59 billion dollars into various project categories until now. The most popular categories that investors choose to support are Technology (1.05 billion dollars), Games (1.49 billion dollars) and Design (1.27 billion dollars). One of the reasons that these categories are the most popular can be the pandemic situation in the world since some industries became more attractive to investors. The following analysis will be done only considering these three of the most popular investment categories.

In addition, usually, these projects from the three most popular categories are not only being supported but also are successfully funded at the end of campaigns. Successful Technology projects got 926 million dollars, Games projects received 1.39 billion dollars, and successful Design projects got 1.17 billion dollars. This can be reflected in Figure 3 .

Comparing all successfully funded projects on the Kickstarter platform to successfully funded projects from only three main categories (technology, games and design), it was found that this group of technology, games and design projects gain $69 \%$ of overall successful funding.

Crowdfunding platforms mainly earn their revenues from fees taken from projects. Kickstarter platform has an All-or-nothing approach, so this platform receives fees only from successfully funded projects. Kickstarter takes a $5 \%$ fee from every successfully funded project from project owners. In Figure 4, it is shown Kickstarter received fees from the most popular projects groups - technology, games and design. For simplicity, these received fees will be considered as Kickstarter revenues for the given period.

In the next paragraph, the forecast for the crowdfunding platform revenues should be conducted. Again, the forecast will cover only the fees taken from most successful project groups - technology, games and design.

\subsection{Forecasting crowdfunding platform revenues using the ARIMA model}

With the purpose to do the forecasting for crowdfunding platform revenues, the ARIMA model for time series will be used. The ARIMA model will be performed using statistical software Python.

To use the ARIMA model, the described procedure should be followed. First, the specific ARIMA model should be identified. Second, parameters of autoregressive and moving average should be estimated. Third, diagnostic checking should be done to whether the chosen model fits the data well. And fourth, forecasting should be performed. 
To start with, the data set and required statistical packages are imported to the program. Kickstarter revenues received from the three most successful project groups were used as a data set (refer to Figure 4).

Later, the stationarity of the data set should be checked. To find out this, a mean and standard deviation of the time series should be calculated. This can be done using data.rolling.mean or data.rolling.std functions. As a result, it was found that to calculate mean and standard deviation, three first values of time series should be used. Figure 5 summarises these results, and it can be seen that the mean and standard deviation are not stationary.

To support that time series is not stationary, the Dickey-Fuller test was performed. This test is used to find if the time series has a unit root. This is made by performing adfuller function from module statsmodels.tsa.stattools in Python. Dickey-Fuller test uses AIC information criteria, which shows the quality of the created model. Dickey-Fuller test results are given in Table 1. Test results show that the $p$-value is higher than 0.5 . Test statistics are far from critical values, which means that the analysed time series is not stationary.

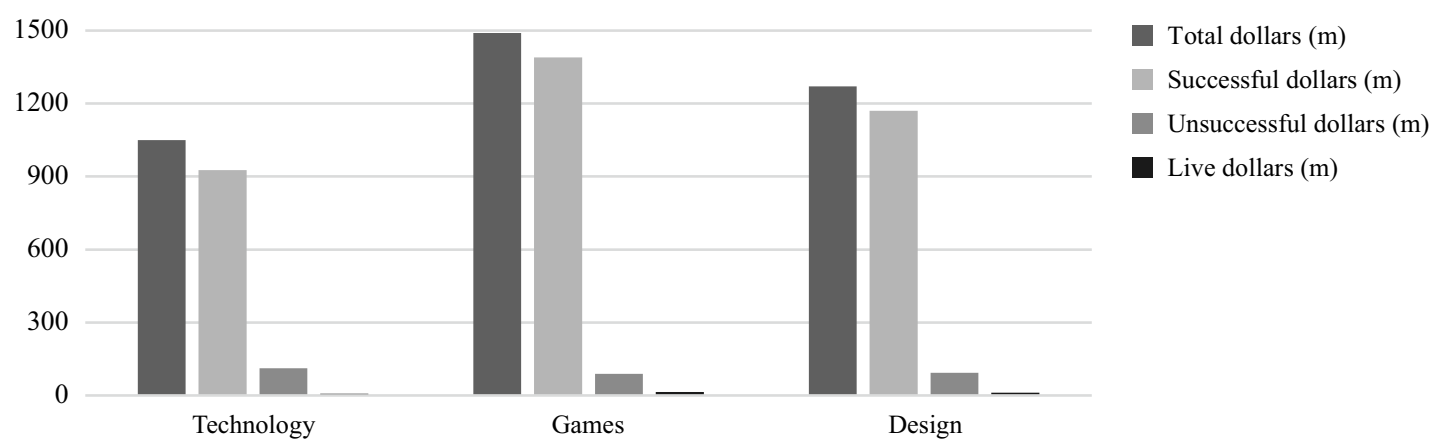

Figure 3. Successful crowdfunding platform project categories (source: created by authors based on Kickstarter data)

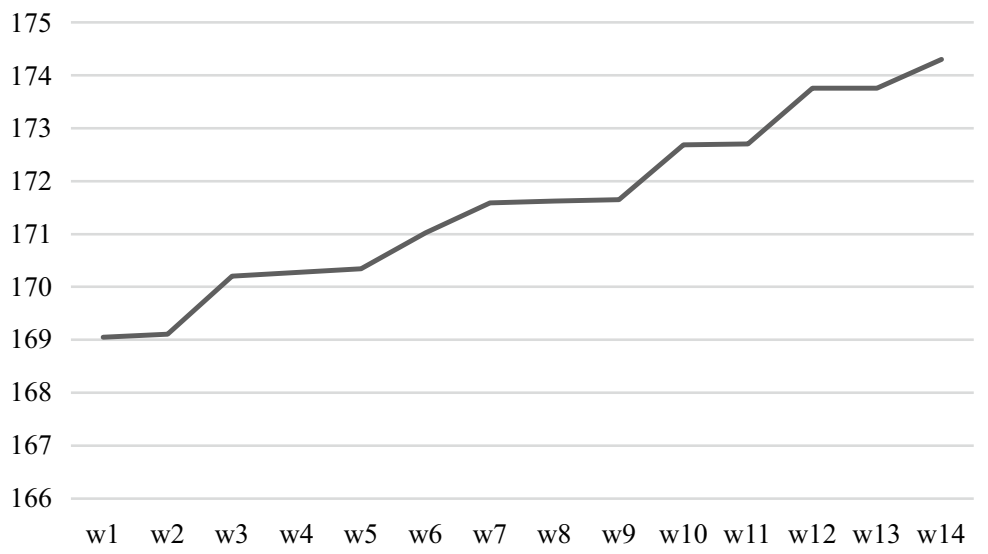

Figure 4. Crowdfunding platform Kickstarter calculated revenues in millions (Source: calculated by authors based on Kickstarter data)

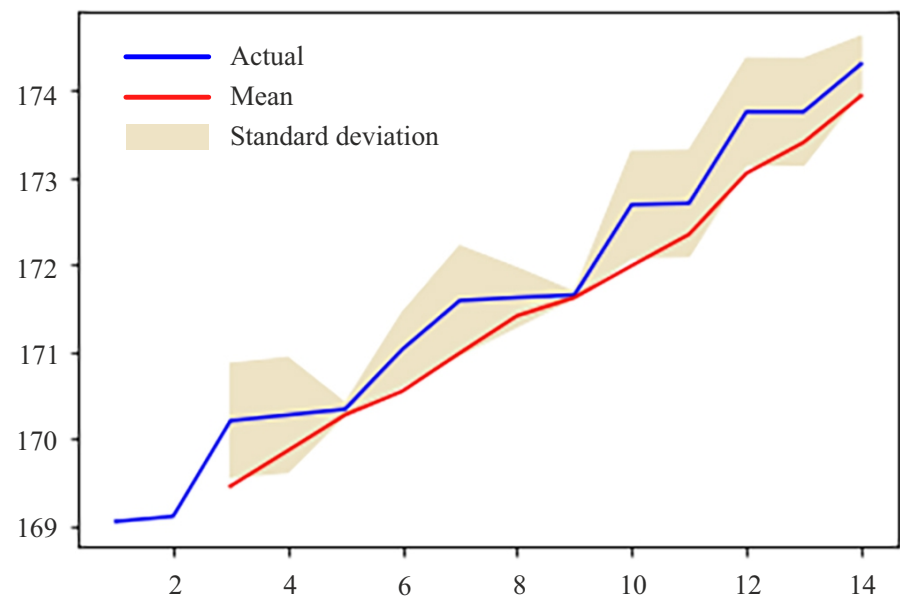

Figure 5. The mean and standard deviation for stationarity checking (source: calculated by authors using Kickstarter data)
Table 1. Dickey-Fuller test results (source: calculated by authors using Kickstarter data)

\begin{tabular}{|l|c|}
\hline \multicolumn{1}{|c|}{ Dickey-Fuller test results } & \\
\hline Test Statistic & -0.364637 \\
\hline p-value & 0.915838 \\
\hline \#Lags Used & 1.000000 \\
\hline Number of Observations Used & 12.000000 \\
\hline Critical value (1\%) & -4.137829 \\
\hline Critical value (5\%) & -3.154972 \\
\hline Critical value (10\%) & -2.714477 \\
\hline dtype: float64 & \\
\hline
\end{tabular}




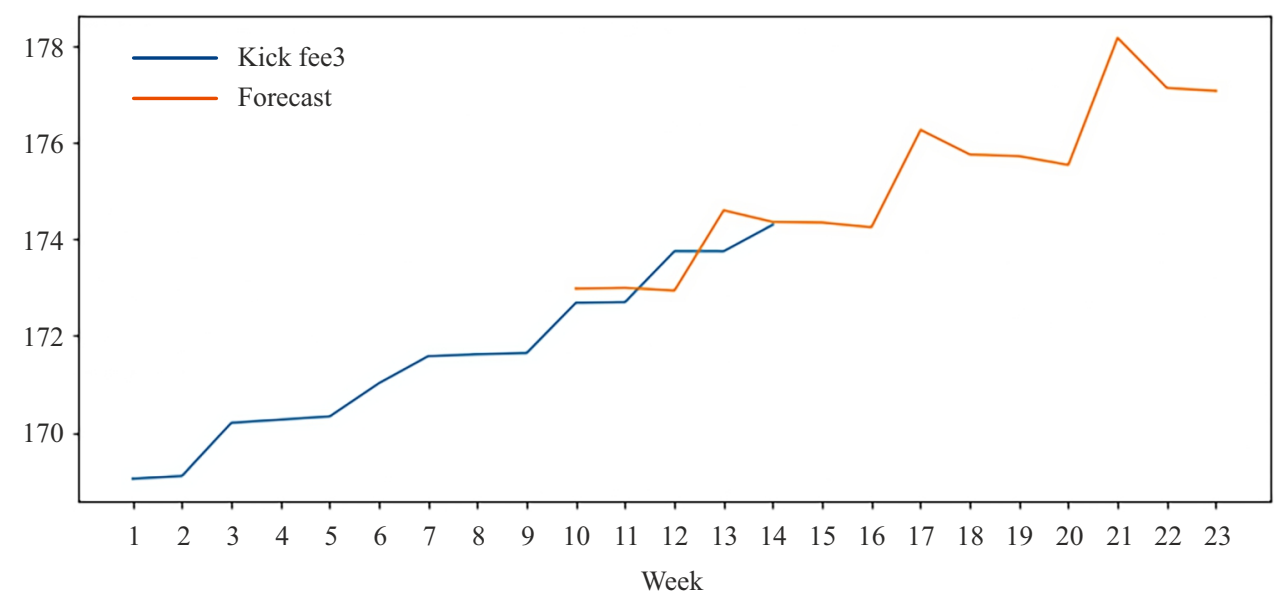

Figure 6. Crowdfunding platform revenue forecast from most successful crowdfunding platform project categories (source: forecasted by authors)

Time series were transformed into logarithmic with log function. Having logarithmic values, the mean and standard deviation was calculated again. Then seasonal decomposition was made in order to get time series stationary.

Modelling ARIMA, it is required to find which $p, d$, and $q$ values will be used for forecasts. The best fit for values are $p=1, d=0, q=1$. To use model ARIMA, the auto_arima function from module pmdarima was performed in Python. After all, the model was checked whether it fits the data set. The predicted model was evaluated using MSE and RMSE. The calculations showed that MSE was equal 0.3505 and RMSE was equal 0.5920. Finally, with function predict, the forecast of the analysed time series was found. The forecast is shown in Figure 6.

As can be seen from Figure 6, the forecast shows that the crowdfunding platform revenues will continue to grow from the most successful and most popular project categories. Moreover, the forecast shows that there should be several peaks in week 13, week 17 and week 21. In these periods, revenues should rise; thus, crowdfunding platforms should select specific campaigns from successful categories while investors should invest in those campaigns during the peak periods. Moreover, the forecast gives some downturns as well. Week 16 and week 20 are not very successful in terms of crowdfunding platform revenues. However, it is worth mentioning that the accuracy of the forecast decreases when we add more forecasting periods. In future research, it would be good to check the accuracy of the forecast with lower forecasting periods.

\section{Results and discussions}

In this research, the ARIMA model was chosen and built to forecast crowdfunding platform revenues. Taken fees from successful campaigns were considered as the main revenues for crowdfunding platforms. The study indicated that the best fit for values was $p=1, d=0, q=1$. Therefore, the final ARIMA model was designed as ARIMA $(1,0,1)$ model. Results from the forecast show that the ARIMA model can be used to forecast crowdfunding platform revenues. According to the forecast, revenues will continue to rise from the most successful and most popular campaign categories. ARIMA $(1,0,1)$ model fits well. Moreover, crowdfunding platforms should more often select crowdfunding projects from the most successful categories like technologies, games or design. To the best of our knowledge, we could not find any other publications regarding revenue forecasting using the ARIMA model. Moreover, it is hard to find forecasting on crowdfunding platform revenues. Generally, revenues were forecasted by several authors. Queenan et al. (2009) proposed Holt's double exponential smoothing (DES) method. Pimentel et al. (2018) compared the revenue-generating capabilities of the bid price allocation method and the nested network method in hotel revenue management. Kryvovyazyuk et al. (2020) used Discounted Cash Flow Model (DCFM), Capital Asset Pricing Model (CAPM), Terminal Growth Rate Model (TGRM), Gordon Growth Model (GGM) and Exit Multiple (EM) in order to make revenue forecasting for IT sector companies. For future research, it might be interesting to check these models on crowdfunding platform revenue forecasting.

\section{Limitations}

The main limitation of this research is the dataset. Daily data was taken from the Kickstarter platform for 14 weeks. With the intention to have more precise calculations and forecast, there should be taken a longer period of time. The second limitation might be the ARIMA model itself. With other dataset and diverse interpretation, it is possible to choose different ARIMA model. Thirdly, the accuracy of the forecast decreases when a higher number of forecasting 
periods is taken. Thus, it should be considered the right number of forecasting periods very carefully. And finally, forecasts were made from the three most successful project categories together. In the future it would be good to forecast each project category separately to see the trends for investing.

\section{Conclusions}

The total launched campaigns on the Kickstarter crowdfunding platform were analysed. It was found that only $38 \%$ of campaigns are successfully funded. Kickstarter is mostly known as a creative project crowdfunding platform that suggests 15 different campaign categories to invest in. Until now, it was invested 5.59 billion dollars in total. After analysing more in-depth, the three most popular and most successful project categories were identified. They are technology (1.05 billion dollars), Games (1.49 billion dollars) and Design (1.27 billion dollars). The analysis showed that these three campaign groups together gain $69 \%$ of successful funding.

The fees taken from the most successful project categories were calculated. In this research, received fees were considered as the main revenues for the crowdfunding platform. In order to do the forecasting for crowdfunding platform revenues, the ARIMA model was identified and built. The analysis showed that the best fit for values was $p=1, d=0, q=1$; as a result, the final ARIMA model for forecasting was ARIMA $(1,0,1)$. The model ARIMA was built using Python statistical software.

The forecast shows that the crowdfunding platform revenues will continue to grow from the most successful and most popular project categories. Consequently, investors should continue to support technology, games and design categories the most, while crowdfunding platforms should give more attention to these categories when choosing new projects to launch on the platform.

\section{References}

Ahlers, G. K. C., Cumming, D., Günther, C., \& Schweizer, D. (2015). Signaling in equity crowdfunding. Entrepreneurship: Theory and Practice, 39(4), 955-980. https://doi.org/10.1111/etap.12157

Belleflamme, P., Omrani, N., \& Peitz, M. (2015). The economics of crowdfunding platforms. Information Economics and Policy, 33, 11-28. https://doi.org/10.1016/j.infoecopol.2015.08.003

Butticè, V., Colombo, M. G., \& Wright, M. (2017). Serial crowdfunding, social capital, and project success. Entrepreneurship: Theory and Practice, 41(2), 183-207. https://doi.org/10.1111/etap.12271

Colombo, M. G., Franzoni, C., \& Rossi-Lamastra, C. (2015). Internal social capital and the attraction of early contributions in crowdfunding. Entrepreneurship: Theory and Practice, 39(1), 75-100. https://doi.org/10.1111/etap.12118

Courtney, C., Dutta, S., \& Li, Y. (2017). Resolving information asymmetry: Signaling, Endorsement, and crowdfunding success. Entrepreneurship: Theory and Practice, 41(2), 265-290. https://doi.org/10.1111/etap.12267

Cumming, D. J., \& Zhang, Y. (2017). Are crowdfunding platforms active and effective intermediaries? SSRN. https://doi.org/10.2139/ssrn.2819845

Fan-Osuala, O., Zantedeschi, D., \& Jank, W. (2018). Using past contribution patterns to forecast fundraising outcomes in crowdfunding. International Journal of Forecasting, 34(1), 30-44. https://doi.org/10.1016/j.ijforecast.2017.07.003

Gerber, E. M., \& Hui, J. (2013). Crowdfunding: Motivations and deterrents for participation. ACM Transactions on Computer-Human Interaction, 20(6). https://doi.org/10.1145/2530540

Gierczak, M. M., Bretschneider, U., \& Leimeister, J. M. (2014, December). Is all that glitters gold? Exploring the effects of perceived risk on backing behavior in reward-based crowdfunding [Conference presentation]. 35th International Conference on Information Systems "Building a Better World Through Information Systems", ICIS 2014. Auckland, New Zealand.

GeeksforGeeks. (n.d.). Python | ARIMA model for time series forecasting. Retrieved December 13, 2020, from https://www.geeksforgeeks.org/python-arima-model-for-time-series-forecasting/

Gujarati, D. N. (2004). Basic Econometrics. McGraw-Hill/Irwin.

Hagedorn, A., \& Pinkwart, A. (2016). The financing process of equity-based crowdfunding: An empirical analysis. In D. Brüntje \& O. Gajda (Eds.), Crowdfunding in Europe. FGF Studies in Small Business and Entrepreneurship (pp. 71-85). https://doi.org/10.1007/978-3-319-18017-5_5

Kickstarter. (n.d.-a). About - Kickstarter. Retrieved December 13, 2020, from https://www.kickstarter.com/about?ref=global-footer

Kickstarter. (n.d.-b). Kickstarter Stats. Retrieved December 13, 2020, from https://www.kickstarter.com/help/stats?ref=about_subnav

Kryvovyazyuk, I., Smerichevskyi, S., Myshko, O., Oleksandrenko, I., Dorosh, V., \& Visyna, T. (2020). Application of Combined Modeling Methods for Estimating and Forecasting the Business Value of International Corporations. International Journal of Management (IJM), 11(7), 1000-1007.

Löher, J. (2017). The interaction of equity crowdfunding platforms and ventures: an analysis of the preselection process. Venture Capital, 19(1-2), 51-74. https://doi.org/10.1080/13691066.2016.1252510

Lukkarinen, A., Teich, J. E., Wallenius, H., \& Wallenius, J. (2016). Success drivers of online equity crowdfunding campaigns. Decision Support Systems, 87, 26-38. https://doi.org/10.1016/j.dss.2016.04.006

Mendes-Da-Silva, W., Rossoni, L., Conte, B. S., Gattaz, C. C., \& Francisco, E. R. (2016). The impacts of fundraising periods and geographic distance on financing music production via crowdfunding in Brazil. Journal of Cultural Economics, 40(1), 75-99. https://doi.org/10.1007/s10824-015-9248-3 
Mohammadi, A., \& Shafi, K. (2018). Gender differences in the contribution patterns of equity-crowdfunding investors. Small Business Economics, 50(2), 275-287. https://doi.org/10.1007/s11187-016-9825-7

Pimentel, V., Aizezikali, A., \& Baker, T. (2018). An evaluation of the bid price and nested network revenue management allocation methods. Computers and Industrial Engineering, 115, 100-108. https://doi.org/10.1016/j.cie.2017.10.026

Queenan, C. C., Ferguson, M., Higbie, J., \& Kapoor, R. (2009). A comparison of unconstraining methods to improve revenue management systems. Production and Operations Management, 16(6), 729-746. https://doi.org/10.1111/j.1937-5956.2007.tb00292.x

Ralcheva, A., \& Roosenboom, P. (2019). Forecasting success in equity crowdfunding. Small Business Economics, 55(1), 39-56. https://doi.org/10.1007/s11187-019-00144-x

Salomon, V. (2016). Emergent models of financial intermediation for innovative companies: from venture capital to crowdinvesting platforms in Switzerland. Venture Capital, 18(1), 21-41. https://doi.org/10.1080/13691066.2015.1079953

Shim, J. K. (2000). Strategic business forecasting. CRC Press. https://doi.org/10.4324/9781482279184

Skirnevskiy, V., Bendig, D., \& Brettel, M. (2017). The influence of internal social capital on serial creators' success in crowdfunding. Entrepreneurship: Theory and Practice, 41(2), 209-236. https://doi.org/10.1111/etap.12272

Thies, F., Wessel, M., \& Benlian, A. (2014, December). Understanding the dynamic interplay of social buzz and contribution behavior within and between online platforms - Evidence from crowdfunding [Conference presentation]. 35th International Conference on Information Systems "Building a Better World Through Information Systems", ICIS 2014. Auckland, New Zealand.

Vroomen, P., \& Desa, S. (2018). Rates of return for crowdfunding portfolios: theoretical derivation and implications. Venture Capital, 20(3), 261-283. https://doi.org/10.1080/13691066.2018.1480265

Zhang, D., Li, Y., Wu, J., \& Long, D. (2018). Online or not? What factors affect equity crowdfunding platforms to launch projects online in the pre-investment stage? Entrepreneurship Research Journal, 9(2), 1-17. https://doi.org/10.1515/erj-2017-0176

Zhang, P. G. (2003). Time series forecasting using a hybrid ARIMA and neural network model. Neurocomputing, 50, $159-175$. https://doi.org/10.1016/S0925-2312(01)00702-0

Zhao, Q., Chen, C. Der, Wang, J. L., \& Chen, P. C. (2017). Determinants of backers' funding intention in crowdfunding: Social exchange theory and regulatory focus. Telematics and Informatics, 34(1), 370-384. https://doi.org/10.1016/j.tele.2016.06.006 